\title{
Tidal Energy and Large-Scale Fish Farming, Benefits of Novel Tsunami and Flooding Barriers
}

\author{
Hans J. Scheel
}

\begin{abstract}
Loss of lives and huge damages due to tsunamis and flooding can be prevented by the principle of the stable vertical wall submerged at minimum $20 \mathrm{~m}$ below sea level. Tsunami impulse waves are reflected and the build up of catastrophic tsunami waves near the coast is suppressed. A novel technology applies steel fences with horizontal anchors and stabilizes them by inserting rocks from above. A double-pontoon method allows efficient erecting such barriers starting from the coast. Hanging surge stoppers protect the barrier top against highest storm waves. The barriers form large seawater reservoirs to be used for tidal energy (by turbines fixed inside the barrier), for energy storage by pumps between reservoirs, and for large-scale fish farming, or the reservoirs are filled up for land reclamation. This architecture allows to build stable dikes, to prevent erosion of coasts and artificial islands, and to protect bridge pillars and offshore platforms.
\end{abstract}

Index Terms-Tsunami barriers, submarine architecture, tidal energy, energy storage, fishing farms, land reclamation.

\section{INTRODUCTION}

The devastating tsunamis December 26, 2004 at the shores of Indian Ocean killing more than 200'000 people and in Honshu, Japan March 11, 2011 with more than 20'000 fatalities and political consequences from the Fukushima catastrophe are still remembered. Despite expensive tsunami warning systems summarized by Annunziato et al. [1] and breakwaters and other protecting buildings on shore, the tsunami waves of height up to $38 \mathrm{~m}$ caused direct damages during run-up and secondary damages from swimming debris and return flow. Also the flooding catastrophes caused by Katrina at Louisiana, by Sandy in New York and New Jersey, and recently by Kajiki on the Philippines have demonstrated the risks of typhoons and hurricanes which are expected to raise with the climate change.

An overview of tsunamis was given by Bryant [2], who specifically discussed the risk for large cities with population above 15 million like Los Angeles, Mumbai, New York, Osaka and Tokyo, for 50 cities with more than 2 million, and for many coastlines. It is a matter of time that a large tsunami may cause immense fatalities and damage. The physics of tsunami was discussed by Levin and Nosov [3], and Strusinska [4] reviewed recent investigations about tsunami wave characteristics and countermeasures. Characteristics of the Indian Ocean Tsunami, the inherent energy of earthquakes and tsunami, and the catastrophic effects of the 2004 tsunami in eight countries have been explained in Murty et al. [5]. Types and functions of coastal structures

Manuscript received January 12, 2014; revised March 7, 2014.

Hans J. Scheel is with Scheel Consulting Company, 8808 Pfäffikon, Switzerland (e-mail: hans.scheel@bluewin.ch). were presented by Burcharth and Hughes [6], and Takahashi [7] discussed construction and stability features of partially vertical breakwaters. Typical failures of composite breakwaters in Japan have been presented by Takahashi et al. [8], and Arikawa et al. [9] discussed in detail the failure mechanism of the world's largest breakwater of Kamaishi during the Honshu tsunami 2011.

In the following, a tsunami protection barrier will be described which effectively will save human lives and avoid devastating damages. Extended vertical barriers along the coasts will not only protect, but have great advantages which may partially compensate the construction costs, such as tidal and wave energy, energy storage, large-scale fishing farms, and land reclamation.

\section{PRinciple of The Vertical wall}

The failure of even the largest breakwaters caused by tsunami and by very high waves from cyclones suggests to analyze the fundamental hydrodynamic phenomena of tsunami wave development and of the interaction of waves with breakwaters. Tsunami waves are impulse waves which are formed from sudden vertical displacements of the ocean bottom related to earthquakes, or they have their origin from landslides, from underwater volcanic eruptions, or they are initiated from meteorites, asteroides, or from man-made explosions. Their initial wavelength is much longer than the typical depth of the ocean of $4 \mathrm{~km}$, the initial amplitude (height of the wave) is limited to a few tens of centimeters and rarely exceeds $1 \mathrm{~m}$, and the travelling speed is about $700 \mathrm{~km}$ per hour. The catastrophic tsunami sea waves of typically 4 to $10 \mathrm{~m}$ height, with extreme height of more than $40 \mathrm{~m}$, are formed when the impulse waves reach the decreasing water depth at the coast. The long wavelength and the speed of the impulse wave are then reduced and compensated by increased amplitude. By the law of energy preservation the kinetic energy of the impulse wave is transformed to potential energy by increasing the height of the tsunami wave. Their velocity $\boldsymbol{c}$ is given in a first approximation [3] by

$$
\boldsymbol{c}=\sqrt{ }(\boldsymbol{g} \times \boldsymbol{h})
$$

with $\boldsymbol{g}$ gravitation acceleration and $\boldsymbol{h}$ the water depth, as shown in Fig. 1a. The product of the amplitude or wave height $\boldsymbol{h}_{\mathbf{0}}$ squared times velocity $\boldsymbol{c}$ is constant:

$$
h_{0}^{2} \times c=\text { constant } .
$$

The Tsunami wave height $h_{1}$ as a function of water depth respectively wave speed from Fig. 1a is shown in Fig. 1b. 
with the parameters $c=713 \mathrm{~km}$ per hour at a water depth of $4000 \mathrm{~m}$ for two typical examples of wave heights of $\boldsymbol{h}_{\mathbf{0}}=0.3$ $\mathrm{m}$ and $\boldsymbol{h}_{\mathbf{0}}=0.6 \mathrm{~m}$ at $\boldsymbol{h}=-4000 \mathrm{~m}$, and with an extreme example of $\boldsymbol{h}_{\mathbf{0}}=1.0 \mathrm{~m}$ at $4000 \mathrm{~m}$ water depth. The Tsunami wave heights are increasing slightly until water depth is less than about $200 \mathrm{~m}$, and only at water depth around $100 \mathrm{~m}$ the wave height increases above $2.5 \mathrm{~m}$ for the initial wave height of $1.0 \mathrm{~m}$ at $4 \mathrm{~km}$ depth. The consequence is that the Tsunami barrier can economically be erected off-shore at water depth between $20 \mathrm{~m}$ to $200 \mathrm{~m}$ which normally is still on the continental shelf, and extends several meters above sea level at high tide depending on the highest expected waves from Tsunami and storms.
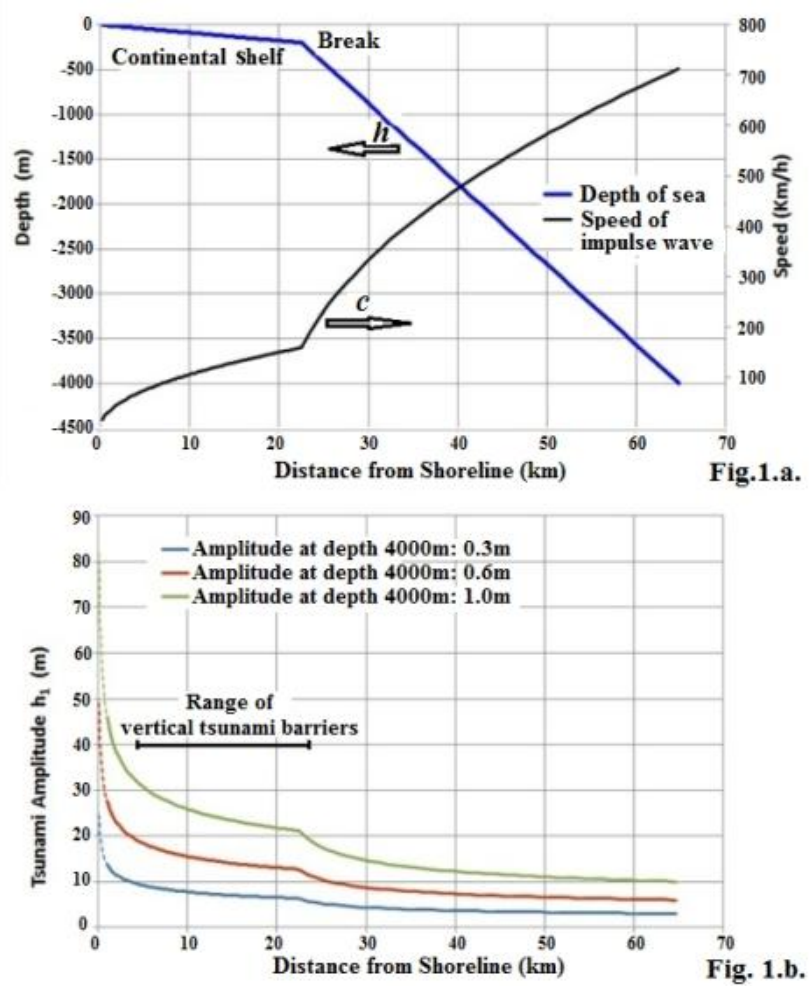

Fig. 1.a. Speed of tsunami impulse wave as a function of water depth. Fig. 1.b. Tsunami amplitude h1 as a function of depth of Fig. 1.a.

In exceptional localities the initial off-shore Tsunami wave may reach $1.5 \mathrm{~m}$ or more so that geophysicists and seismologists should estimate the maximum expected vertical displacement of the ocean floor. This then indicates the preferred position and depth of the tsunami barrier and its height above sea level. Several existing breakwaters try to reduce the catastrophic effect of high Tsunami waves near the coast after these waves have been formed. The prominent example is the Kamaishi breakwater which was erected in a bay where by the funnel effect the tsunami wave height had increased by the geometrical factor and by the low water levels on both coastal sides of the barrier. Also the large foundation mound with a slope of $33 \mathrm{~m}$ length will have contributed to an increased tsunami wave height and its destructive forces.

The new Tsunami barrier described below is remote from the shore so that the funnel effect of bays and fjords is prevented. It is recognized that a stable vertical barrier immersed in the sea by about $30 \mathrm{~m}$ below sea level is required to reflect the tsunami impulse waves before the high tsunami waves can be formed. This is demonstrated in Fig. 2 where the vertical wall reflects the impulse waves and where the roughness of the seaward front of the wall dissipates some of the wave energy. The gap between shore and barrier is filled up to reclaim new land and to stabilize the barrier by heavy masses [10]. This depth of $30 \mathrm{~m}$ is a compromise between safety and economy, $50 \mathrm{~m}$ would be still more effective in case of a mega-tsunami occurring simultaneously with a cyclone.

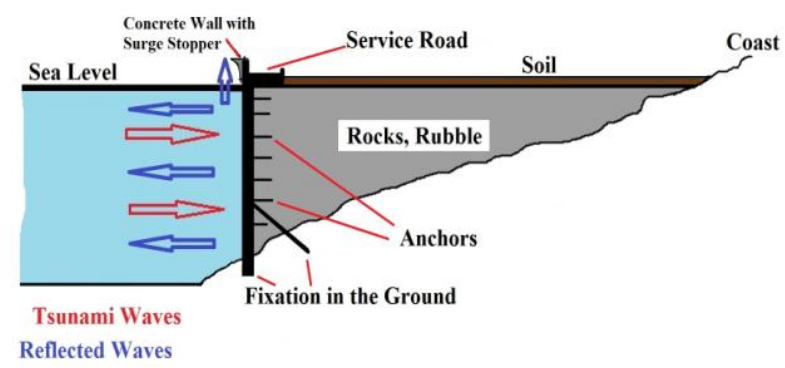

Fig. 2. Vertical tsunami barrier with reflected tsunami impulse waves and with land reclamation, schematic cross section.

Deep-sea construction using conventional concrete technology is in principle possible in view of the special concrete types which are resistant towards seawater; however this approach is very costly. A novel submarine architecture was invented recently [10]-[14] and allows to erect at modest costs and at high production rates such vertical walls of extreme stability by design and by weight. This is based on high-strength steel fences and on rocks.

\section{CONCEPT OF VerticAl TSUNAMI BARRIERS}

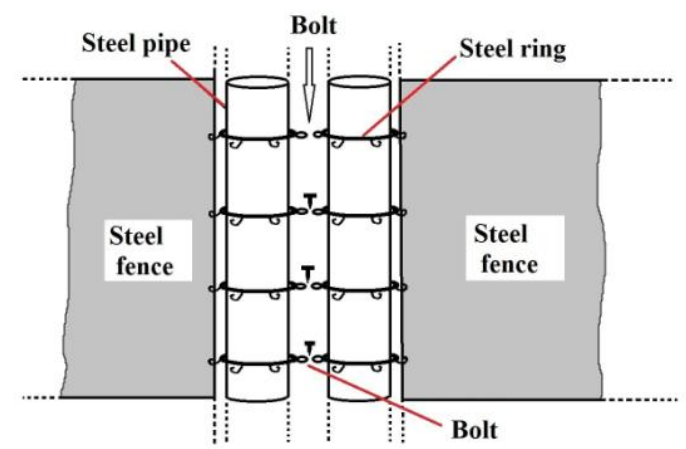

Fig. 3. Two steel pipes with steel rings to connect two fences with inserted bolts, schematic side view.

There are three different ways to build barriers from high-strength steel fences and rocks which are inserted from top to hold the fences in the vertical position. Before this procedure the seafloor is dredged or cleaned by water pressure to remove soft ground and sand. Alternatively heavy foundations are inserted into the sandy ground. In the first approach the steel fence with attached horizontal anchors is lowered into the sea and stabilized by rocks inserted from above. Vertical steel pipes (filled with concrete) or steel profiles are first inserted deeply into the sea floor. The sides of steel fences have rings with hooks which are gliding down along the pipes and connect two parallel fences. Two parallel tubes facilitate independent insertion of parallel fences and 
later their repair or replacement. The mechanical horizontal connection of the fences is achieved by bolts introduced into the hooks between the tubes as shown in Fig. 3 .

In the second method two parallel fences with distance holders are simultaneously inserted into the sea and stabilized by rocks inserted into the gap between the fences. These fences are horizontally connected and filled with rocks to long tsunami barriers along the coast, for example $800 \mathrm{~km}$ along the coast of Honshu, Japan or $50 \mathrm{~km}$ in front of New York harbor.

The third method consists of elongated gabions, cages of steel fence filled with rocks. These gabions are deposited from top in order to build a continuous compact wall. However, experiences with breakwaters containing heavy caissons showed [7] that by high pressures from waves these caissons glide or tilt.

Steel fences are produced in many countries. Wire thickness of about $4 \mathrm{~mm}$ often gives sufficient strength, especially since the saltwater-corrosion-resistant steel has excellent tensile strength. For exceptional requirements, for example above sea-level to withstand the storm-waves, the ROCCO steel net of Geobrugg AG Switzerland may be applied using in addition its advantage of high elasticity. This is beneficial also to survive earthquakes, besides its stability against highest storm waves. The stability of the barrier can be increased by steel ropes crossing in front of the barrier surface, the ropes being fixed to the fence or anchors.

All steel components are produced from the same saltwater-corrosion-resistant steel, for example chromiumand molybdenum-containing low-carbon steels with European numbers 1.4429 (ASTM 316LN), 1.4462, 1.4404, 1.4571 (V4A), ASTM 316 or 316L. All metal alloys should have the same composition in order to prevent electrolytic reactions and corrosion at the connecting points. Furthermore, long-time corrosion may be further reduced by coating.

Besides stability, the reflectivity of the seaward side of the tsunami barrier is important. A total reflection of the impulse waves would harm the opposite coast. For instance a strong tsunami hitting Japan East coast would be reflected towards Hawaii and the American continent. Therefore, the low reflectivity of the fence-rock structure will be preferred and have the additional advantage of partial energy dissipation of the impulse wave. Further scattering of tsunami waves may be achieved by zigzag or undulating structures of the seaward side of the tsunami barrier. It would be interesting to investigate the relation between surface roughness and submarine reflectivity.

\section{CONSTRUCTION OF DOUBLE-FENCE TSUNAMI BARRIERS}

The construction of stable vertical walls in open sea including the transport of fences, rocks and concrete is quite difficult with delivery and working from ships. It follows a simple approach starting with double-pontoons from the coast, along with measures to attenuate disturbing storm waves [14], [15].

After building a stable ramp road at the coast to a sufficient depth, two parallel pontoons with a gap in between are connected to this ramp road. In order to carry the heavy loads of trucks with rocks, these central pontoons are connected by a stable steel frame on top with larger external pontoons as shown in Fig. 4. The lower horizontal connections between the pontoons are arranged at the horizontal ends of the fences, so that these are interconnected below these connection arms. Now special trucks deliver the rolls of fences which are lowered on both sides of the central pontoons as shown in Fig. 5 followed by trucks to deliver the rocks and to insert them through the gap into the sea. For the top of the barrier extending above sea level the pontoons have to move to the next construction site so that the space between the fences above sea level can be filled with rocks from ships.
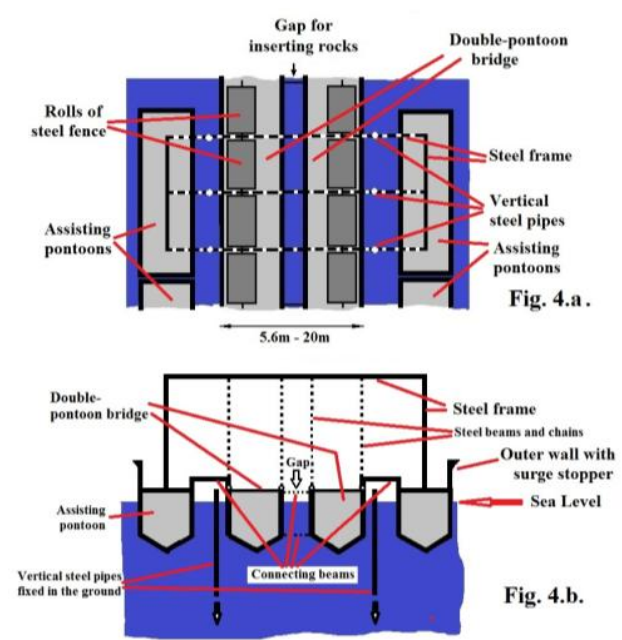

Fig. 4. Double-pontoon bridge with assisting pontoons to insert steel fences and rocks: a. top view, b. cross section.

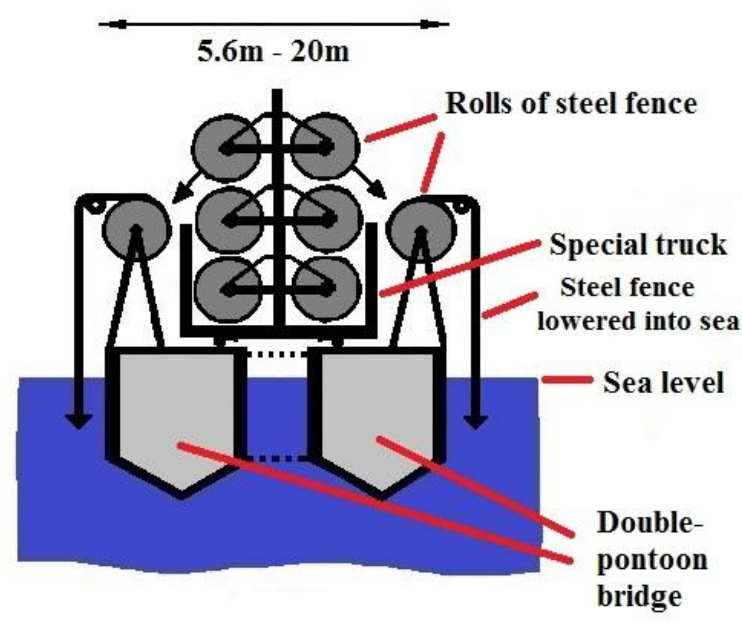

Fig. 5. Schematic cross section of rolls of steel fence delivered by truck and lowered from the double pontoon bridge into the sea.

In the next step special trucks deliver concrete and reinforcement steel for building the concrete wall and the concrete supply road on top of the steel-fence-rock barrier. The empty trucks move on a single- or double-pontoon bridge to the coast, see Fig. 6.

The size of the rocks (or rubble) should fit into the gap between the pontoons, but should not pass through the openings of the fence and best be in the range of $40 \mathrm{~cm}$ to $90 \mathrm{~cm}$. Rounded rocks tend to move later so that rocks with edges are preferred. In order to settle the rocks, vibrations by 
weights hitting the sides of the barrier can be applied [14], [15]. During the rock deposition, a further stabilization is achieved by periodic insertion of gravel to fill the gaps between the rocks, for instance every $10 \mathrm{~m}$ to $20 \mathrm{~m}$ height of rocks. Alternatively, or additionally, horizontal nets of steel or of other saltwater-resistant material can be periodically deposited onto the rocks in order to minimize their later movements and to increase the overall stability of the barrier.

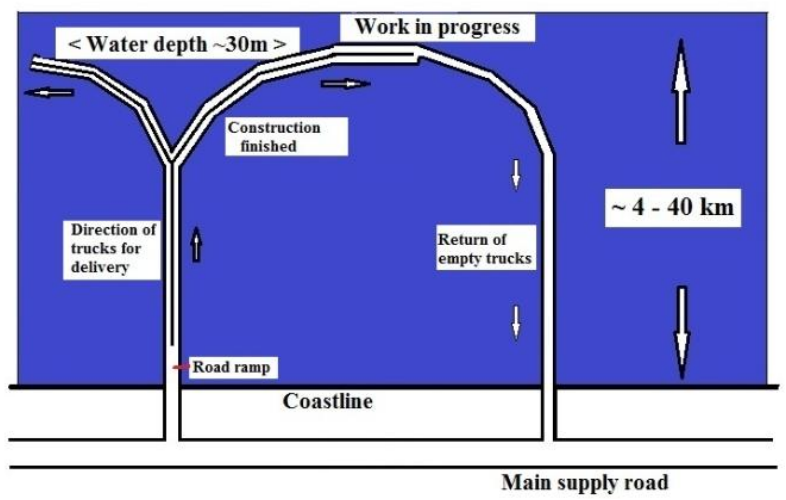

Fig. 6. Schematic top view of double-pontoon bridges for trucks, with rocks or steel-fence rolls, which after delivery return to the coast on single-pontoon bridges (assisting pontoons not shown).

In view of frequent storm waves up to $10 \mathrm{~m}$ or higher, the construction work has to be protected by attenuation of the waves [14], [15]. This is achieved by large-area stable steel fences floating on the sea by pontoons which are fixed at the seafloor by heavy foundations or weights, or by anchors, as schematically shown in Fig. 7. The water permeability of these nets and their size (typically between $50 \mathrm{~m}$ and 500m) needs to be optimized for achieving sufficient attenuation of the storm waves.

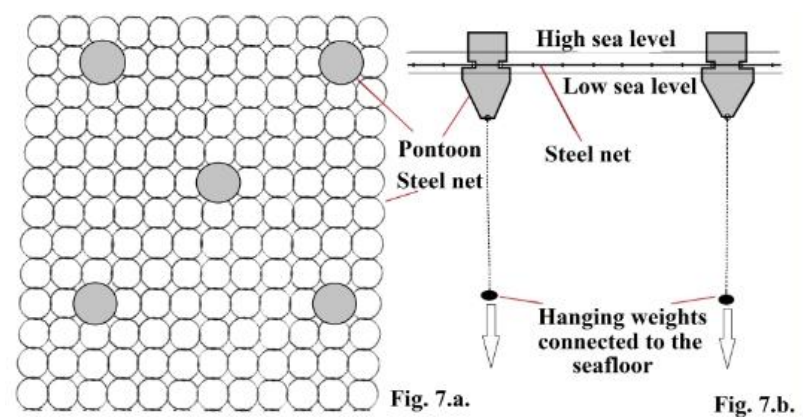

Fig. 7. Wave-attenuating steel fence floating on the sea surface by means of pontoons fixed with steel beams and chains to the seafloor, a. schematic top view, b. cross section.

\section{STRUCTURE OF THE TSUNAMI BARRIERS}

The preferred height (depth) of the barriers discussed above is $30 \mathrm{~m}$, and the width will be between $5.6 \mathrm{~m}$ and $20 \mathrm{~m}$ depending on stability and risk analyses and on local seafloor characteristics. A schematic cross section of a double-fence wall is shown in Fig. 8.

Horizontal anchors directed towards the harbor and stabilized by rocks provide enhanced stability of the tsunami barrier. The top concrete wall is protected by a hanging wave or surge stopper which is transported by means of the hook and fixed to the vertical wall. This surge stopper of concrete can be replaced in the first phase to test construction materials and later when it is eroded. Scrouting of sand from below the barrier due to water currents can be reduced by a small "foot" seaward at the bottom of the barrier.

The vertical steel beam gives the possibility for later heightening when needed for increased sea level or storm surges. The concrete supply and service road allows to transport the surge stoppers, to monitor the barrier, and to provide access to the fishing farms and for the energy turbines and pumps discussed below.

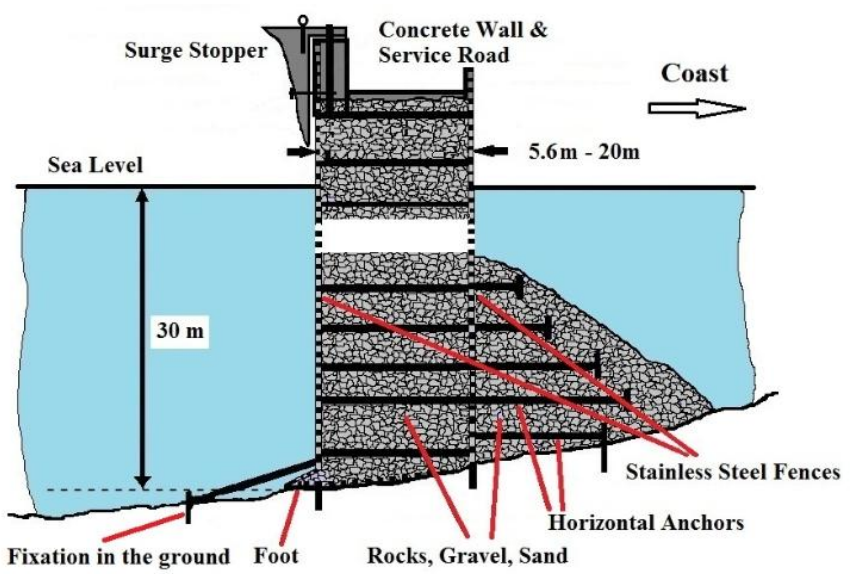

Fig. 8. Double-fence barrier of $5.6 \mathrm{~m}$ to $20 \mathrm{~m}$ thickness with concrete wall, surge stopper and service road, schematic cross section.

A thick tsunami barrier with surge stopper is shown in Fig. 9 where the top concrete wall is stabilized by rocks on the harbor side.

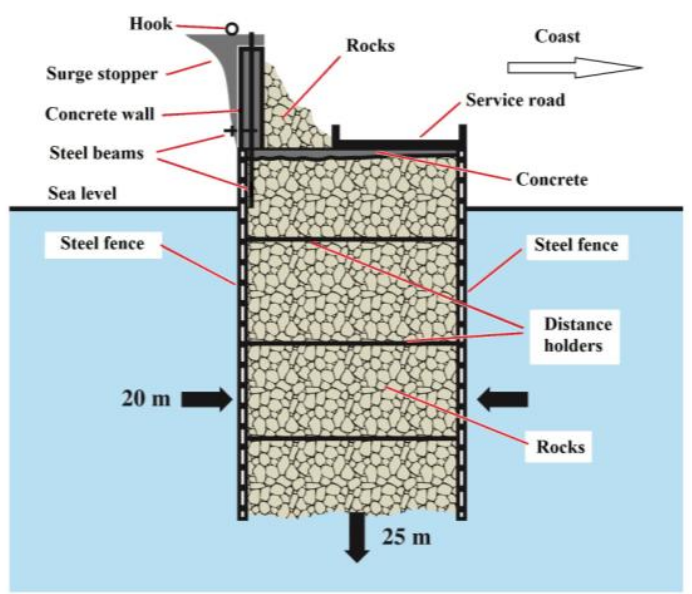

Fig. 9. Double-fence barrier of $20 \mathrm{~m}$ thickness with concrete wall stabilized with rocks, schematic cross section.

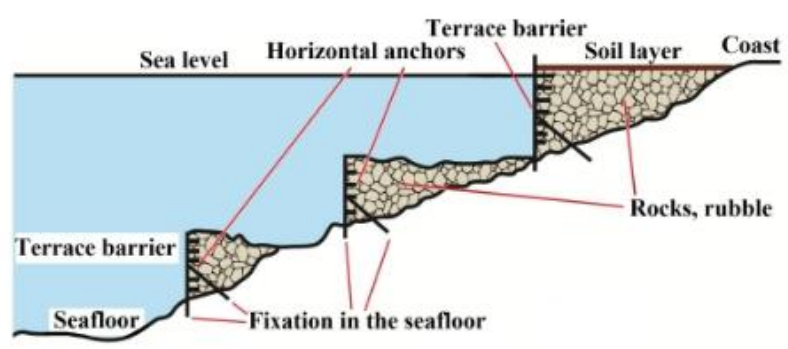

Fig. 10. Terrace of tsunami barriers to save rocks and to reclaim new land, schematic cross section.

The tsunami barriers of Fig. 8 and Fig. 9 require large 
quantities of rocks. The terrace structure shown in Fig. 10 reduces the rock quantity and still gives the choice of land reclamation, or using the reservoir between barrier and coast for energy or for fish farming.

When navigation or beaches have to be preserved, the tsunami barrier will have reduced height and end about 5 to $10 \mathrm{~m}$ below the low-tide sea level, as shown with Fig. 11. Obviously, signals have to be mounted in order to indicate the barrier. In this case, however, the beaches are not protected against oil spill and other contamination from the sea.

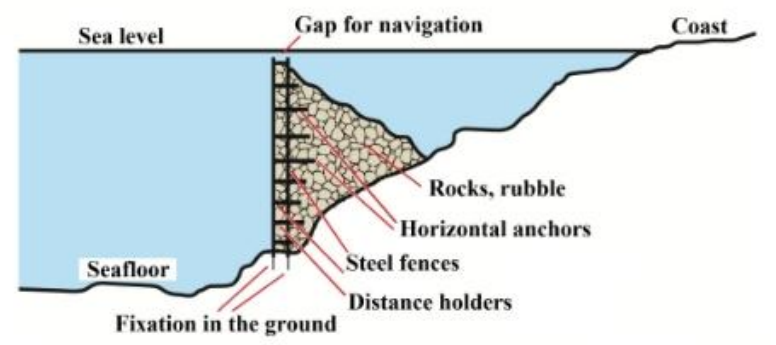

Fig. 11. Tsunami barrier with a gap for navigation, schematic cross section.

An alternative for offshore fishing navigation is schematically shown in Fig. 12 where barrier-supply roads form a channel which connects the harbor with open sea. The exit to the sea is protected against tsunami and highest storm waves by an inclined barrier. The two reservoirs are used as fishing farms or serve for generating tidal energy or provide energy storage by pumping.

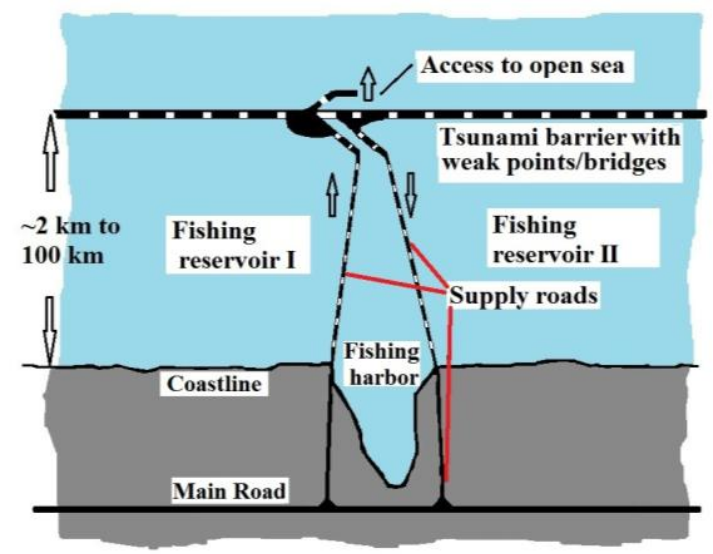

Fig. 12. Schematic top view of tsunami barrier with service road, supply roads, fishing reservoirs, and access from fishing harbor to the open sea.

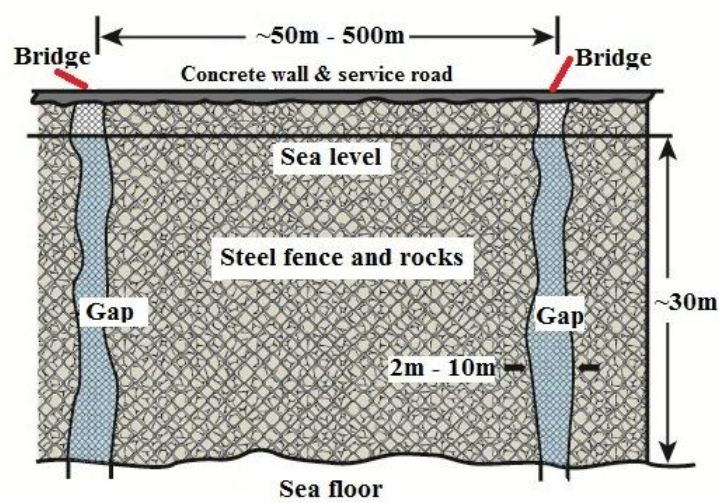

Fig. 13. Tsunami barrier with weak gaps closed by fishing nets, schematic side view.
The very long tsunami barriers may fail in a severe earthquake so that repair would require a large effort. In order to overcome this problem weak spots are provided in the barriers in order to facilitate repair. These openings with concrete bridges and walls and fisher nets are shown in Fig. 13.

\section{Protection OF SUBMARINE AND OFFSHORE BUILDINGS}

Double-fence barriers may also be used as annular tube structures for offshore platforms, for pillars of bridges, and for wind-power plants [11]-[15]. Double-wall pipe structures with rocks inserted between the inner and the outer pipe extending above sea level protect the central pillars of offshore platforms or of wind-power plants from Tsunami waves and from high sea-waves caused by storms. In such a double-pipe structure the outer and the inner fences are connected and thus closed at the bottom. The construction is done in analogy to the Tsunami barrier construction. This annular structure is arranged when the platform pillars or the stand of the wind-power plant have only partially been raised. However, also existing pillars for instance of bridges can be protected by producing the double-fence-rock structure on site. The height of the protection pipe and the distance between inner and outer fence, and thus the outer diameter and the mass including the filled-in rocks, depend on the expected highest sea waves. In most cases the horizontal distance between the fences will be in the range $1 \mathrm{~m}$ to $5 \mathrm{~m}$, and a height of $2 \mathrm{~m}$ to $10 \mathrm{~m}$ above sea level at high tide is recommended.

The upper rim of the outer fence should have warning signals or signal lights for navigation (the same as for the Tsunami barriers ending below sea level).

The new submarine architecture can also be useful for deep-sea mining. Double-fence-rock structures can be lowered to the seafloor in order to define, separate and mark specific areas and in order to mark paths and directions. Geographic marking spots can easily be identified. Another application will be for dikes and levees [14], [15], this will be discussed in a forthcoming publication.

\section{RENEWABLE ENERGY FROM TIDES AND ENERGY STORAGE BY PUMPING}

A remarkable power plant using tidal energy from turbines in a barrier combined with pumps for energy storage has been built in Rance, Northern France 1967, has a capacity of 240 MW, and is still successfully delivering electricity to the grid. Another recently installed (2011) large tidal power plant is the Sihwa Lake Tidal power station in South Korea with 254 MW capacity. Both plants use barriers with turbines inside.

Tidal stream generators require high flow velocities for instance in the channel of Strangford Lough, North Ireland of up to $4 \mathrm{~m} / \mathrm{s}$. However, the generators have gaps between them which have to be compromised with the effect that a higher density of "water mills" in a tidal turbine farm reduces the energy output per turbine [16].

Barrier systems are more efficient than tidal stream generators, typically $70 \%$ to $85 \%$, but due to their reputation of very high construction costs they have not found wide 
application. This may change now with the new and efficient barrier construction technology introduced here and when the reservoirs behind the barriers are, simultaneously with tidal power generation, applied as energy storage systems by pumping, as this has started with the power plant in Rance. Pumped-storage hydroelectricity requires valleys in mountainous landscapes and building of large dams. It accounts for $99 \%$ of bulk energy storage worldwide corresponding to $127,000 \mathrm{MW}$ [17]. However, future development will slow down due to inherent limits and resistance of people. Thus, pumped-storage hydroelectricity along the seaside is another benefit of tsunami protection barriers.

A schematic system of seawater reservoirs obtained between tsunami barriers and the coast [15] is shown in Fig. 14. Reservoir I uses only tidal energy which is intermittent, even when both flow directions of high and low tide are used, and thus depends on large tidal height differences between $4 \mathrm{~m}$ and $12 \mathrm{~m}$ as they occur at the French Northwestern and British Western coast. Most other coasts worldwide have tidal height differences of less than $3 \mathrm{~m}$.

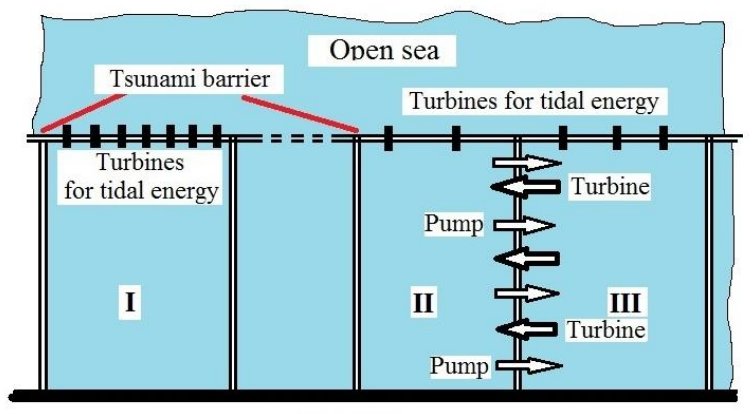

Coastline

Fig. 14. Schematic top view of reservoirs for tidal energy (I), and for combined tidal energy and energy storage by pumping (II, III).

The combination of tidal energy and energy storage by pumping is shown with reservoirs II and III. Both have tidal turbines in their tsunami barriers, but the main advantage are the pumps and turbines in the separation barrier between reservoir II and III. In a phase of surplus electricity, for instance during night, water is pumped from reservoir II up into reservoir III. The turbines are activated when (high-cost) electricity is needed using the potential energy of water of reservoir III. By optimized process control a continuous supply of electricity can be provided, a relief for grid control. Installing offshore Tsunami barriers along extended coastlines provides huge reservoirs with a potential of generating tidal energy and to establish enormous possibilities of energy storage by pumped-storage hydroelectricity.

The installation of the wave-damping steel nets for protection of the construction site [14], [15] gives the possibility to install wave-energy converters at the net for two reasons, for assisting the wave-attenuating action and to generate renewable electricity from waves. The problems for this technology have been its reliability and its high costs. A proposal [18] tries to combine a traditional rubble mound breakwater with reservoirs and a multistage turbine, using the energy of overtopping water and thereby increase the efficiency of the breakwater. This concept requires further analysis.

\section{FISHING FARMS}

A large fraction of the sea water reservoirs between coastline and Tsunami barrier can be used for fishing farms, for instance for salmon, bluefin tuna, sea flounder etc. These water reservoirs will be partially connected with the ocean, so that fresh oxygenated water is provided. Conventional fishing nets or metallic nets will prevent escape of fish through the open "weak points" in the long barriers of Fig. 13. On the other hand these openings can be closed by gates in case of oilspill or other contamination from the sea. Extended fishing nets allow to separate different sizes of fish. In certain areas the application of copper-alloy nets will be used to prevent fouling. For example the North-East coast of Japan protected by $800 \mathrm{~km}$ Tsunami barriers can be divided into sections divided by supply roads according to the boundaries of Prefectures. An alternative arrangement for the supply roads allows navigation from the cities and fishing harbors to the open ocean as schematically shown in Fig. 12. The access to the open sea is protected by a short inclined Tsunami barrier which stops the direct move of the Tsunami wave into the harbour. The supply roads are on top of double-fence-rock barriers of 4 to $5 \mathrm{~m}$ thickness which have gaps with bridges and fences, the latter with openings according to the separated fish sizes, see Fig. 15a and 15b. These gaps can be closed by gates with fences or with completely closing gates. Fish farming in seawater reservoirs will compensate the reduced fish population in the ocean due to overfishing.

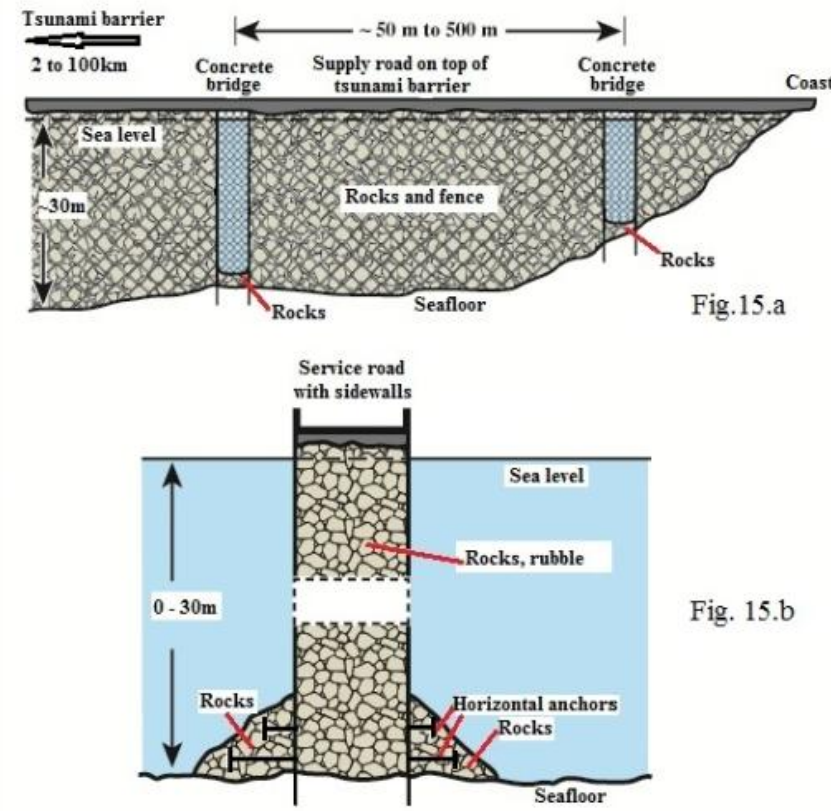

Fig. 15 a, b. Schematic side view (a) of a supply road between coast and tsunami barrier with gaps and fences covered by bridges, and a schematic cross section (b) of the double-fence supply road of about $4 m-5 m$ thickness.

\section{CONCLUSION}

The new submarine architecture gives all countries the possibility to protect the coastal population against tsunami and flooding. Ecological advantages are protection of fauna and flora including corals against oil-spill and other 
contamination. At the same time the tsunami barriers and the large seawater reservoirs will become relevant for the large problems of mankind due to population growth and the consequences of climate change: nutrition crisis, limits of energy and energy storage. The large projects will stimulate industries and provide job growth.

\section{ACKNOWLEDGMENT}

The author thanks H. Schüttrumpf/RWTH Aachen and M. Toulios/ NTUA Athens, for helpful discussions.

\section{REFERENCES}

[1] A. Annunziato, G. Franchello, and T. Groeve, "Response of the GDACS system to the Tohoku earthquake and tsunami of 11 March 2011," Sci. Tsunami Hazards, vol. 31, pp. 283-296, 2012.

[2] E. Bryant, Tsunami, the Underrated Hazard, $2^{\text {nd }}$ ed. Chichester UK: Springer \& Praxis Publishing, 2008.

[3] B. Levin and M. Nosov, Physics of Tsunamis, Springer Science + Business Media B.V., 2009.

[4] A. Strusinska, Hydraulic Performance of an Impermeable Submerged Structure for Tsunami Damping, Stuttgart: IBIDEM-Verlag, 2011.

[5] T. S. Murty, U. Aswathanarayana, and N. Nirupama, The Indian Ocean Tsunami, London UK: Taylor \& Francis, 2006.

[6] H. F. Burcharth and S. A. Hughes, "Types and functions of coastal structures," Engng. Manual, US Army Corps of Eng. Rep. EM 1110-2-1100 Part IV change 3, ch. 2, September 2011.

[7] S. Takahashi, "Design of vertical breakwaters, short course of hydraulic response and vertical walls," in Proc. $28^{\text {th }}$ International Conference on Coastal Engineering, Cardiff, Wales UK, July 7, 2002.

[8] S. Takahashi, K. Shimosaki, K. Kimura, and A. Suzuki, "Typical failures of composite breakwaters in Japan", in Proc. $27^{\text {th }}$ International Conference on Coastal Engineering, 2000, ASCE, pp. 1885-1898.

[9] T. Arikawa, M. Sato, K. Shimosako, I. Hasegawa, G. S. Yeom, and T. Tomita, "Failure mechanism of Kamaishi breakwater due to the Great East Japan Earthquake Tsunami," in Proc. Coastal Engineering, 2012, vol. 33, pp. 1-13.

[10] H. J. Scheel, "New type of tsunami barrier," Natural Hazards, vol. 70, pp. 951-95, 2014.

[11] H. J. Scheel, "Structure and method for protection against tsunami-waves and high sea-waves caused by storms," WIPO/PCT No. WO 2013/030810 A1, March 7, 2013.
[12] H. J. Scheel, "Submarine construction for tsunami and flooding protection, for fish farming, and for protection of buildings in the sea," EP Patent Appl. 13162698.8, April 8, 2013.

[13] H. J. Scheel, "Submarine construction for tsunami and flooding protection, for fish farming, and for protection of buildings in the sea," U.S. Patent Appl. 13/861, 608, April 12, 2013.

[14] H. J. Scheel, "Double-pontoon-bridge construction of submerged barriers and of off-shore roads," WIPO/PCT Patent Appl. PCT/IB2013/059511, October 21, 2013.

[15] H. J. Scheel, "Submarine construction for tsunami and flooding protection, for tidal energy and energy storage, and for fish farming," Patent Appl. in 9 countries, February 8, 2014.

[16] C. Christian and R. Vennel, "Efficiency of tidal turbine farms," in Proc. Coastal Engineering, 2012, vol. 33, pp. 1-10.

[17] The Electric Power Research Institute (EPRI), "Energy storage-packing some power," The Economist, March 3, 2011.

[18] D. Vicinanza, D. Stagonas, G. Müller, J. H. Norgard, and T. L. Andersen, "Innovative breakwater design for wave energy conversion," in Proc. Coastal Engineering, 2012, vol. 33, structures 1, pp. 1-12.

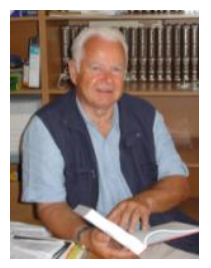

Hans J. Scheel is a Swiss citizen with chemical background. He has worked 25 years in Universities in Switzerland, Brazil as a full professor and Italy and 21 years in chemical, electronic and machine industries in Germany, Switzerland and USA. After retirement from Swiss Federal Institute of Technology (ETH), he was a visiting professor/invited scholar at Osaka and Tohoku Universities, Japan and at Shandong University, China. His Accelerated Crucible Rotation Technique ACRT is worldwide applied and demonstrated the importance of forced convection in crystal production, in contrast to the early concept of reduced convection and microgravity. $\mathrm{He}$ was the co-organizer of European and International conferences and organized four International Workshops on Crystal Technology between 1998 and 2008. He has given 150 international invited lectures, is the author of 140 technical publications and patents and co-author and editor of seven books in the field. For his inventions and achievements he received the Dr. of Engineering (DSc) from Tohoku University Japan (1995), was elected member of the Russian Academy of Engineering Sciences (1996), and got awards from Swiss (1972), British (2000) and Korean (2001) Crystal Growth Associations and from IBM $(1972,1975,1982)$. After retirement he started Scheel Consulting company and, besides consulting, got involved in education of crystal technologists for energy and in Tsunami barriers. www.hans-scheel.ch. 